\title{
ЭФФЕКТИВНОСТЬ ИНСТИТУЦИОНАЛЬНЫХ ПРЕОБРАЗОВАНИЙ КАК ОСНОВА РАЗВИТИЯ ИННОВАЦИОННОЙ ДЕЯТЕЛЬНОСТИ В ЛЕСНОЙ ОТРАСЛИ
}

АНнотАция. Актуальность исследования условий инновационного развития лесной отрасли обусловлена необходимостью повышения ее эффективности. Объектом исследования являются инновации и инновационная деятельность в лесной отрасли. Предметом исследования - оценка эффективности инноваций и институциональных преобразований в лесной отрасли как направления инновационной деятельности. Целью исследования является разработка теоретических и методических положений, раскрывающих роль институциональных преобразований в развитии инновационной деятельности и оценка состояния инноваций в лесной отрасли. Анализ и оценка эффективности инноваций и институциональных преобразований является важным инструментом стратегического планирования инновационного развития лесной отрасли. Предлагается регрессионная модель оценки эффективности инноваций и институциональных преобразований основанная на экспертных оценках. Разработаны схема и программа инновационно-институциональных преобразований лесной отрасли. Определены ключевые инновации, мероприятия и этапы реализации инновационно-институциональных преобразований. Предложены методы стимулирования инновационной деятельности в лесной отрасли.

кЛючЕВЫЕ СЛОВА. Инновации; инновационная деятельность; институциональные изменения; оценка эффективности; лесная отрасль.

ИНФОРМАЦИЯ О СТАТЬЕ. Дата поступления 4 марта 2016 г.; дата принятия к печати 21 октября 2016 г.; дата онлайн-размещения 30 ноября 2016 г.

D. V. Dayneko

Irkutsk Science Center of SB RAS,

Irkutsk, Russian Federation

\section{EFFICIENCY OF INSTITUTIONAL CHANGES AS A BASIS OF DEVELOPING INNOVATIVE ACTIVITY IN TIMBER INDUSTRY}

ABSTRACT. The topicality of investigating innovative development terms in the timber industry is determined by the necessity of increasing its efficiency. The object of the investigation is innovations and innovative activity in the timber industry. The subject of the investigation is assessing efficiency of innovations and institutional changes in the timber industry as a direction of the innovative activity. Analysis and assessment of innovations and institutional changes is an important tool of strategic planning of innovative development of the timber industry. The article offers a regressive model of assessing efficiency of innovations and institutional changes, based on expert evaluations. It develops a scheme and a program of innovative and institutional changes of the timber industry. It specifies key innovations, measures and stages of implementing innovative and institutional changes. It offers methods of promoting the innovative activity in the timber industry.

KEYWORDS. Innovations; innovation activities; institutional changes; forest industry; effectiveness evaluation.

ARTICLE INFO. Received March 4, 2016; accepted October 21, 2016; available online November 30, 2016.

Сегодня в экономике России происходят глобальные изменения, обусловленные как необходимостью инновационного развития, так и санкциями ЕС и США, что требует поддержания отечественного инновационного образования и ориента-

\section{Baikal Research Journal}


ции на развитие инноваций. Развитие инновационной деятельности в нашей стране предполагает становление новых отношений, основанных на институциональных изменениях. В новых условиях предметом внимания ученых, как теоретиков так и практиков, а также всех заинтересованных специалистов, становятся факторы, обеспечивающие конкурентоспособность товаров и услуг, технологий и систем управления, хозяйствующих субъектов и отраслей, регионов и экономики страны в целом.

Актуальность исследования условий инновационного развития лесной отрасли обусловлена необходимостью повышения ее эффективности. Данные статистики свидетельствуют о том, что растет доля убыточных предприятий, снижается уровень налоговых платежей, увеличивается износ основных фондов отрасли. В то же время имеется хороший ресурсный потенциал, научные разработки и инновационные проекты, которые могут служить основой для инновационного развития отрасли. Кроме того, Россия занимает ведущее положение в мире по заготовке леса, что говорит о возможностях международного сотрудничества в данной сфере, особенно в связи с сокращением лесосырьевых баз в мире и глобализацией проблемы сохранения лесов.

Вследствие непродуманных действий в лесозаготовке практически уничтожены леса Европы и большинства центральных российских областей. Под угрозой полного уничтожения находятся леса Бразилии, Мексики, Китая и других стран. Вопрос устойчивого лесопользования приобретает особую актуальность в регионах России, которая на протяжении многих лет занимает первое место среди лесозаготовительных стран. Возникает угроза разрушения существующих экосистем, ухудшения климата, водного баланса, а с экономической точки зрения, и стратегического потенциала страны, в следствии исчерпания возобновимых и невозобновимых природных ресурсов. Именно сохранение природного потенциала страны является необходимым условием сдерживающим экологический кризис на Земле.

Особую актуальность данное исследование приобретает в связи с обострением проблем глобального потепления и сокращения лесосырьевых баз в международном потреблении. Значительная роль лесной отрасли и ее производственных предприятий в национальной экономике, позиция среди других отраслей и перспективы международного сотрудничества, усиливают важность данного исследования.

Таким образом, объектом исследования являются инновации и инновационная деятельность в лесной отрасли. Предметом исследования - оценка эффективности инноваций и институциональных преобразований в лесной отрасли как направления инновационной деятельности. Целью исследования является разработка теоретических и методических положений, раскрывающих роль институциональных преобразований в развитии инновационной деятельности и оценка состояния инноваций в лесной отрасли.

Теоретические основы инновационной деятельности рассматривались в трудах таких российских экономистов, как Е. В. Балацкий [1], М. В. Грачева [2], P. А. Фатхутдинов [3] и других ученых, исследующих теоретические и практические проблемы повышения әффективности производства посредством внедрения инноваций. В основе теоретической части работы лежат исследования таких известных институциональных экономистов, как Р. Коуз [4], Д. Норт [5], и других. В России исследования институциональных факторов экономики проводились в трудах А. А. Аузана [6], О. С. Белокрыловой, В. В. Вольчика [7] Н. Я. Калюжновой [8], Р. М. Нуреева, А. Н. Олейника, В. М. Полтеровича [9] и др. Институциональный аспект инновационной деятельности рассматривается в работах таких исследователей, как Й. Шумпетер [10], К. Фримен, Ф. Хайек и других [11]. Институциональные вопросы развития лесного сектора рассматриваются в работах А.В. Колесниковой, Ю.Ш. Блама, Л.В. Машкиной [12].

\section{Baikal Research Journal}

электронный научный журнал Байкальского государственного университета 
Лесной фонд и институциональная структура лесной отрасли. Именно лес являясь исчерпаемым, но возобновимым ресурсом заслуживает особое внимание экологов и экономистов. В эпоху глобализации международных товарных и сырьевых рынков, когда большинство лесов США и Европы переживают стадию консервации, речь должна идти об устойчивом лесопользовании российских лесов, основанном на принципах рационального природопользования.

Россия считается крупнейшей в мире страной по площади лесов. Они занимают $70 \%$ территории страны. Леса России - это богатство нашей страны. По данным Продовольственной и сельскохозяйственной организации $\mathrm{OOH}$, на страну приходится примерно 20,5 \% от общей площади лесов мира и половина хвойных лесов. Большая часть лесных территорий (по 29 \%) заняты мелколиственными и смешанными лесами, выросшими на месте старых вырубок, гарей и сельхозземель, а также северными и горными редколесьями. Чуть меньшая площадь $(21 \%)$ приходится на лиственничные леса. Хвойные леса занимают примерно $19 \%$ лесных земель (при этом 11 \% приходится на еловые, кедровые и пихтовые леса и лишь 8 \% - на сосновые). Самая большая редкость - широколиственные массивы. Их доля всего 3 \%. Общая площадь земель лесного фонда превышает 1,1 млрд га, что составляет 1/4 мировых запасов древесины. На 1 января 2001 г. лесом было покрыто 722 млн га. Общие запасы древесины в российских лесах оцениваются в 75 млрд м ${ }^{3}$. Россия располагает примерно $32 \%$ мировых запасов леса. Если сделать обобщение, то на долю каждого россиянина приходится в десять раз больше лесов чем на американца и в 35 раз больше чем на среднестатистического европейца. Из России экспортируется более 25 \% леса и лесоматериалов ${ }^{1}$ [2].

Наличие в России огромной лесосырьевой базы, уникальная возможность ведения лесозаготовок, позволили осуществить строительство крупных деревообрабатывающих, целлюлозно-бумажных и лесохимических предприятий по производству пиломатериалов, фанеры, древесностружечных и древесноволокнистых плит, бумаги, мебели и других товаров промышленного и бытового потребления.

Сложившаяся институциональная структура лесной отрасли на протяжении многих лет не позволяла лесному бизнесу функционировать эффективно и способствовать устойчивому социально-экономическому развитию территорий. За годы реформ система управления лесами претерпела существенные трансформации. Это было связано и с вопросами собственности и с организационной перестройкой и с изменением лесного законодательства. Институциональное устройство и институциональные преобразования в лесной отрасли тесно связаны с лесной политикой, регулирующей экономические, социальные и экологические последствия лесопользования, включая вопросы собственности и управления. Чтобы стимулировать эффективное предпринимательство в лесном секторе, требуется система мер в сфере национальной и региональной лесной политики, что предполагает необходимость проведения тщательного институционального анализа.

Определяющими институтами в использовании лесных ресурсов являются: институт собственности; инвестиционные институты (банки, страховые компании, фонды, и др.); нормативно-законодательная база лесопользования (законы, постановления, указы, проекты, стандарты и регламенты); сфера налогообложения, включающая правила и нормы, определяющие порядок получения государством части лесного дохода; организационная структура отрасли в целом и организационная структура отдельных предприятий; информационное обеспечение отрасли и организаций; институты, обеспечивающие разработку и реализацию нормативно-правовых документов; институты, обеспечивающие профессиональную подго-

${ }^{1}$ Bсе о российских лесах [Электронный ресурс]. URL: http://www.forest.ru/rus/problems/news.

\section{Baikal Research Journal}

электронный научный журнал Байкальского государственного университета 
товку и образование кадров; неформальные институты, поддерживающие производственные предприятия.

Институциональные проблемы в лесной отрасли. Основные институциональные проблемы лесной отрасли России связанны как с легитимностью потребления лесных ресурсов, так и несоблюдением экологических стандартов, задержкой их принятия и реализации. Имеются существенные противоречия в лесном законодательстве, имеет место наличие конфликтов с другими законами РФ. Открытым остается вопрос распределения прав на лесопользование. В ряде источников отмечается также сложность налоговой политики, которая не способствует развитию экономической деятельности или новым инвестициям; проблема возврата лесных платежей обратно в лесной сектор; наличие коррупционных схем, которые становятся серьезным препятствием для развития деловой активности в лесном секторе; закрытость или отсутствие финансовой информации и статистических данных [13].

Препятствием в эффективном использовании лесов является несовершенство федерального законодательства. С введением нового лесного законодательства субъекты РФ получили полномочия в сфере управления лесами, в частности, на них возложено планирование лесного хозяйства, предоставление в пределах земель лесного фонда лесных участков, организация охраны, защиты и воспроизводства лесов, осуществление государственного лесного контроля и надзора. Однако проблема решения проблем недостатка сырьевой базы, сокращения инвестиций, технической отсталости, дефицита высококвалифицированных кадров, слабого использования технологий по глубокой переработке древесины и других остается открытой. Эффективное развитие отрасли возможно только на инновационной основе, которая требует прежде всего перестройки институциональных отношений.

Анализ трансформационных процессов, происходящих в стране, подтверждает, что при сохранении государственной собственности на лесные ресурсы возможно проявление конфликта, связанного с «правом управления» лесными ресурсами, что вызвано перераспределением данного права в пользу РФ или регионов как субъектов РФ. Формирование отношений между субъектами происходило эмпирическим путем на протяжении 2005-2013 гг., когда наблюдалась существенная тенденция централизации федеральной власти в лесной сфере. Регионы утратили возможность самостоятельно участвовать в совместном ведении применительно к управлению лесным фондом как государственной собственностью. Данная инициатива вызывала мощную негативную реакцию на местах. Правомочия, принадлежавшие субъектам РФ в соответствии с Лесным кодексом, возвратил и расширил Федеральный закон «О внесении изменений в отдельные законодательные акты Российской Федерации в связи с совершенствованием разграничения полномочий» от 31 декабря 2005 г. № 199. В него были включены почти все функции по государственному и хозяйственному управлению лесным фондом. Впоследствии власти в регионе пытались закрепить и расширить свои правомочия, стремились ужесточить условия лесопользования, предлагали отменить аукционы и заменить их на конкурсы. Лесной бизнес выступил против таких изменений, расценивая их как посягательство на свободу экономических отношений [14].

Вопрос о том, какие субъекты будут вести лесное хозяйство или реализовывать отдельные его мероприятия, остается открытым и зависит от принятых на каждом этапе форм лесных отношений с учетом конкретных условий. Однако ответственность за ведение лесных мероприятий, учитывая, что леса России находятся в федеральной собственности, с учетом законодательно принятых требований несет федеральная государственная власть, которая делегирует функции государственного управления лесами уполномоченным органам во всех блоках исполнительной власти.

\section{Baikal Research Journal}

электронный научный журнал Байкальского государственного университета 
Сегодня можно отметить в целом недостаточно әффективное влияние государства на развитие лесной отрасли. Государство, которое может и должно вмешиваться в распределение доходов через систему налогообложения, регулирование цен и оплаты труда, способно влиять на баланс спроса и предложения посредством распределения доходов, создания условий для воспроизводства и возобновления необходимых обществу лесных благ. Проблемы лесной отрасли связаны не только с работой рыночных механизмов, но и мерами государственного регулирования, обеспечивающими баланс между экономическим развитием и охраной окружающей среды.

Современный Федеральный закон «Об особо охраняемых природных территориях", подписанный Президентом Российской Федерации ${ }^{2}$, различает следующие категории особо охраняемых природных территорий: государственные природные заповедники; национальные парки; природные парки; государственные природные заказники; памятники природы; дендрологические парки и ботанические сады; лечебно-оздоровительные местности и курорты. Кроме этого, Правительство РФ, органы исполнительной власти субъектов РФ, органы местного самоуправления могут устанавливать и иные категории особо охраняемых природных территорий (например, зеленые зоны, городские леса, городские парки, береговые линии под охраной, охраняемые ландшафты, биологические станции, микрозаповедники и др.).

Сегодня управление лесами, как и само Лесное законодательство, в России до сих пор остается сложным и запутанным. С этой проблемой сталкиваются и сами работники лесного хозяйства, решая вопрос о применении тех или иных лесохозяйственных нормативов. Зачастую некоторые положения лесных законодательных и нормативных актов вступают в противоречия с земельным, водным и природоохранительным законодательством. Как утверждают сами сотрудники отрасли, не избежали этих недостатков и проекты нового Лесного кодекса РФ. Переход от централизованно планируемой к рыночной экономике без обоснованной программы усугубил сложившийся характер структуры и размещения лесной промышленности, лесного хозяйства, обусловив в конце 1990-х - начале 2000-х гг. беспрецендентый для истории России обвальный спад производства в отрасли.

Институциональные инновации. Институциональные инновации, то есть изменения в институтах - правилах, нормах, механизмах их обеспечения, являются главным типом инноваций. Институциональная инновация как таковая позволяет организациям перестроить себя для масштабирования процессов обучения и генерации лучших инноваций на других уровнях, включая продукты, услуги, бизнес процессы и системы управления для лучшей адаптации к условиям рынка. Они дают организации способность изменять процессы и адаптироваться к рыночным условиям.

Возможность институциональных инноваций позволяет компаниям принимать более инновационное мировоззрение, которое поможет им адаптироваться в этом меняющемся мире. В связи с еще большим открытием такой возможности компании, ориентированные на масштабированную продуктивность, могут полагаться на институциональные инновации как на средство, позволяющее реализовывать другие инновации. Поскольку атрибутом институтов является обучение, институциональные инновации позволяют организациям генерировать необходимые инновации продуктов, услуг, бизнес-структур и иерархии управления.

Проблема институциональных инноваций и их значения в раскрытии механизма институциональных изменений находит свое отражение в теории «индуци-

${ }^{2}$ Об особо охраняемых природных территориях : федер. закон РФ от 14 марта 1995 г. № 33-ФЗ // Российская газета. 1995. 22 марта.

\section{Baikal Research Journal}

электронный научный журнал Байкальского государственного университета 
рованных институциональных инноваций» В. Раттена [15] и Ю. Хайями, в «распределительной» теории институциональных изменений Г. Лайбкепа и различных концепциях таких исследователей как Дж. Найт [16], Д. Норт [5], В. Л. Тамбовцев [17], А. Н. Олейник [18] и др. Институциональный контекст инновационной деятельности рассматривается в работах таких исследователей, как Й. Шумпетер [10], К. Фримен, Ф. Хайек и др. [11].

Оценка эффективности инноваций и институциональных преобразований. Следует отметить, что проблема оценки эффективности инноваций, и институциональных инноваций в частности, долгое время находится в центре внимания ученых-экономистов и практиков. Эффективность инноваций является одним из самых спорных и проблемных аспектов управления инновациями. Она определяется, прежде всего, результатами инноваций. Такими, как, например, способностью сберегать ресурсы и время, требуемые на производство необходимых и предполагаемых полезных эффектов создаваемых продуктов, технических систем, структур.

В результате реализации инноваций могут быть получены следующие виды эффекта: экономический, научно-технический, ресурсный, финансовый, социальный и экологический. Каждый вид эффекта характеризуется комплексом показателей. Например, экономический эффект характеризуется прибылью, приростом объема продаж, улучшением использования ресурсов; социальный эффект - увеличением числа рабочих мест, повышением степени безопасности работников, улучшением условий труда; экологический эффект - снижением выбросов в атмосферу и воду вредных веществ, экологическим улучшением и другим [19].

В настоящее время в практике расчетов эффективности инноваций в основном определяется и учитывается лишь экономическая эффективность. Другие виды эффекта, из-за отсутствия четких методических рекомендаций, недостаточности и недостоверности исходной информации, количественно оценить сложно, поэтому они зачастую не учитываются.

Понятие эффективности инноваций в лесной отрасли также тесно связано с экономической ценностью лесных ресурсов и их оценкой. Вопрос оценки лесных ресурсов является одним из самых актуальных. Определение экономической ценности лесных экосистем может выражаться не только в денежном эквиваленте, поскольку сложно измерить финансовыми мерками такие ценности как, например, красивый ландшафт, пейзаж, пение птиц, и другие рекреационные характеристики лесной природы - все то, что на самом деле обладает чрезвычайно высокой полезностью для индивидов. Тем не менее, рыночная экономика подразумевает оценку следующих функций окружающей среды:

- обеспечение природными ресурсами;

- ассимиляция отходов и загрязнений;

- обеспечение природными благами - рекреационными, эстетическими и другими.

Для оценки эффективности инноваций, включая институциональные инновации которые играют ключевую роль в устойчивом экономическом развитии, нами предлагается кросс-секционный регрессионный анализ [20]. Предлагается следующая модель, основанная на экспертных оценках:

$$
\begin{aligned}
\exists \phi= & b_{0}+b_{1} I_{t z}+b_{2} I_{t o}+b_{3} I_{I T}+b_{4} I_{\text {pro }}+b_{5} I_{\text {nano }}+b_{6} I_{\text {bio }}+ \\
& +b_{7} I_{\text {instform }}+b_{8} I_{\text {instinform }}+b_{9} I_{\text {org }}+b_{10} I_{\text {eco }},
\end{aligned}
$$

где Эф- критерий эффективности развития лесной отрасли; $I_{t z}-$ технологические инновации в лесозаготовке; $I_{t o}-$ технологические инновации в деревообработке; $I_{I T}-$ IT-инновации; $I_{p r o}$ - товарные инновации; $I_{\text {nano }}-$ продуктовые наноиннова-

\section{Baikal Research Journal}


ции; $I_{b i o}-$ продуктовые биоинновации; $I_{\text {instform }}$ - институциональные инновации в формальных институтах; $I_{\text {instinform }}-$ институциональные инновации в неформальных институтах; $I_{\text {org }}$ - организационные инновации; $I_{\text {eco }}-$ экоинновации.

В данном случае в качестве критерия эффективности развития отрасли выбирается количественный показатель развития отрасли. Данная модель удовлетворяет всем предъявляемым требованиям и может быть использована для объяснения (анализа) эффекта инноваций на устойчивое развитие лесной отрасли. Она позволяет оценить:

- насколько эффективно реализуются в лесном бизнесе страны или региона данные инновации;

- оценить роль институциональных инноваций;

- определить важность данных инноваций в развитии лесной отрасли.

Модель оценки роли институциональных инноваций в лесной отрасли может быть представлена следующим образом:

$$
\begin{aligned}
& I M P=b_{0}+b_{1} N_{\text {fed }}+b_{2} N_{\text {reg }}+b_{3} G_{f e d}+b_{4} G_{\text {reg }}+ \\
& +b_{5} I_{\text {fin }}+b_{6} I_{\text {prof }}+b_{7} I_{\text {org }}+b_{8} I_{\text {info }}+b_{9} I_{\text {infinst }},
\end{aligned}
$$

где показатель $I M P$ характеризует прогресс в области реформирования отрасли в условиях глобализации рынков в целом (представляет собой экспертную оценку объема и качество нового законодательства и институтов); $N_{f e d}-$ федеральная нормативно-правовая база; $N_{r e g}-$ региональное нормативно-законодательное обеспечение; $G_{f e d}-$ роль федерального правительства; $G_{r e g}-$ роль регионального правительства (оценивается рыночная ориентация правительства и эффективность управления на региональном уровне); $I_{f i n}-$ финансовый сектор (оценивается уровень независимости, деловых навыков и практики размещения финансовых ресурсов, а также уровень мониторинга и системы платежей); $I_{\text {prof }}$ - профессиональная подготовка и образовательные программы кадров; $I_{\text {org }}$ - организационная структура отрасли и предприятий; $I_{\text {info }}$ - информационно-аналитическая поддержка; $I_{\text {infinst }}$ - неформальные институты (способы контрактации и договорные обязательства, нормы этики и морали, традиции).

Для получения экспертных оценок предлагается анкетный опрос, адресованный нескольким целевым группам: руководителям предприятий и работникам отрасли, представителям исполнительной и законодательной власти, ученым и другим экспертам в области лесного хозяйства и инноваций. Вопросы экспертам о том насколько эффективно реализуются в лесном бизнесе технологические, товарные, институциональные и экологические инновации, позволяют оценить значимость каждого показателя по шкале от 1 до 10 . Опрос осуществляется с учетом уровня компетентности экспертов, а также с использованием сделанной опрашиваемыми экспертами оценки значимости представленных типов инноваций.

Для простоты расчетов в качестве функций $f$ предлагается линейная форма. Для идентификации регрессионных коэффициентов используется традиционный метод наименьших квадратов. Для оценки аппроксимационных свойств получаемых уравнений - коэффициент множественной детерминации $R^{2}$. Полученные значения коэффициента множественной детерминации $R^{2}$ смогут сказать о достаточной точности построенных моделей, и позволят провести их содержательную интерпретацию.

Из модели (1), и согласно полученным оценкам экспертов, был сделан вывод о том, что для устойчивого развития лесной отрасли следует особое внимание обратить на создание новых продуктов, включая био- и нанопродукты. Необходимо совершенствование технологий лесопереработки, а также использования современных методов лесозаготовки с использованием современных IT-технологий.

\section{Baikal Research Journal}


Модель (2) показывает суммарное влияние изменений в выбранных институтах за счет вариаций полученных значений. Согласно оценкам экспертов, инновационное и устойчивое развитие лесной отрасли в большей степени зависит от неформальных институтов, которые включают как договорные обязательства, так и традиции ведения лесного бизнеса. Огромную роль играют решения федерального правительства. Важна надежность финансовых институтов для обеспечения устойчивой работы отрасли.

Эксперты отмечают несовершенство нормативно-правового обеспечения федерального уровня. В то время как распоряжения и постановления местных уровней, согласно мнению экспертов, имеют четкую и последовательную реализацию. Важно отметить необходимость реализации образовательных программ и информационной поддержки отрасли, а также совершенствования организационной структуры отрасли.

Сложность определения эффективности инноваций и институциональных изменений в лесной отрасли в свою очередь обусловлена еще и тем, что институциональные изменения обычно носят качественный характер. Для измерения величин качественного характера, таких как отношение к существующим «правилам игры», надо либо обращаться к методам качественного анализа, либо прибегать к методам преобразования качественных данных в количественные.

Поэтому для оценки эффективности институциональных преобразований также используются: Q-метод, Institutional Analysis Development Framework (IADF), критерии оценки Political Risk Services (PRS measures), Polity IV (constraints on the executive), а также критерии оценки представленные Всемирным Банком развития в проекте «Ведение Бизнеса» (Doing Business).

Развитие предпринимательства в лесной отрасли на основе институциональных преобразований. В сложившейся ситуации роль инновационного предпринимательства в лесной отрасли заключается в переходе от лесозаготовки к созданию новых продуктов на основе изучения и практического освоения инноваций. Роль государства, предполагает содействие получению знаний и комплекса технологий стратегического характера, развитию производства, а также в создании инфраструктуры и благоприятных институциональных условий для инновационной деятельности предпринимателей [21].

Таким образом, в рамках развития лесной отрасли, деятельность инновационного предпринимательства должна быть направлена на решение следующих задач:

- поиск новых путей развития предприятий ЛО на базе инновационных разработок;

- увеличение доли перерабатываемой продукции ЛПК на базе инновационных технологий;

- выпуск новых, лучших по качеству товаров лесоперерабатывающей промышленности, формирование новых потребностей, расширение рынков сбыта;

- повышение эффективности предприятий ЛО за счет интенсивных факторов производства и экологичных технологий;

- оценка и снижение риска от внедрения инноваций [22].

Институциональное устройство и институциональные изменения в лесной отрасли тесно связаны с лесной политикой. Она представляет собой совокупность институтов, регулирующих экономические, экологические и социальные последствия лесопользования, которые включают и вопросы собственности, и управления. Чтобы стимулировать эффективное предпринимательство в лесной отрасли, требуется целая система мер, что является неотъемлемой частью национальной и региональной лесной политики и это (как один из аспектов) предполагает необходимость проведения тщательного институционального анализа. Графическая

\section{Baikal Research Journal}

электронный научный журнал Байкальского государственного университета 
интерпретация предлагаемого процесса инновационно-институциональных преобразований в лесной отрасли представлена на рис. 1.

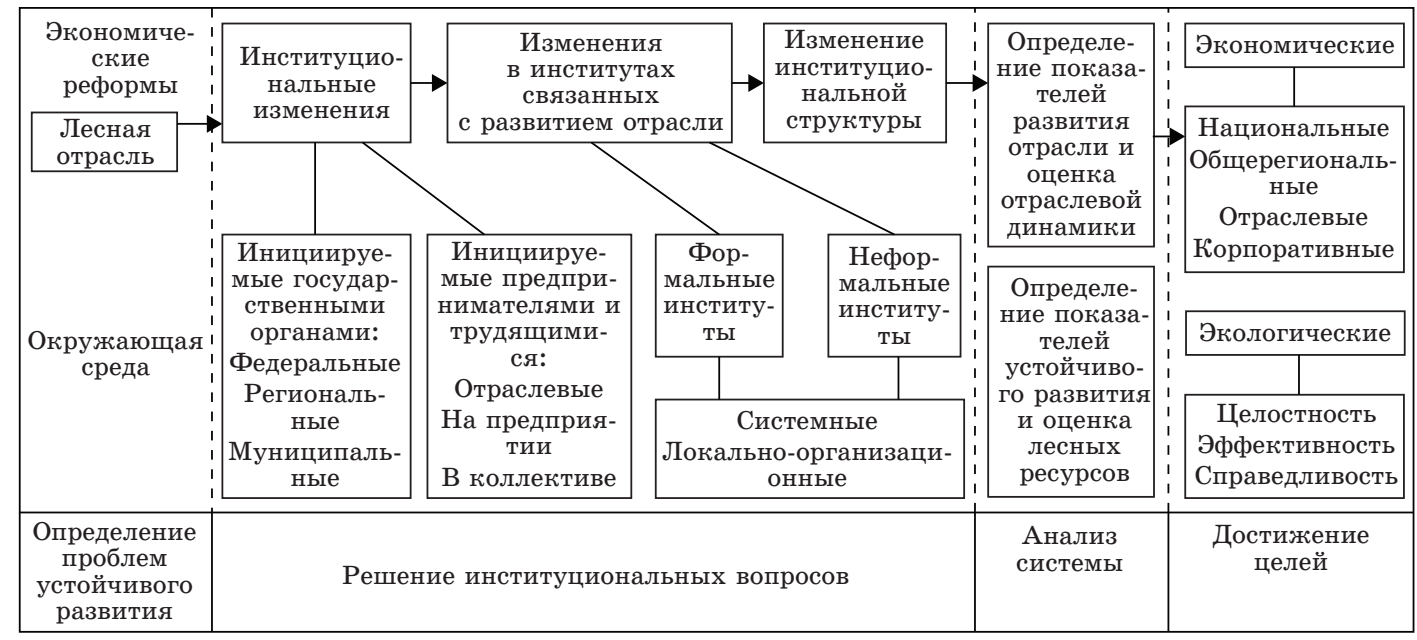

Рис. 1. Инновационно-институциональные преобразования лесной отрасли

Изучение влияния инноваций, включая институциональные (и как основной их части - лесной политики), технологических, продуктовых и экологических на эффективность работы предприятий лесного комплекса является наиболее актуальным. Особенно важным изучение этого вопроса является в настоящее время для оценки эффективности лесозаготовок и их последствий, а также принятия очень важных решений в области лесного экспорта и глубокой переработки древесины.

Необходимость дальнейшего исследования обоснована и тем фактом, что происходящие преобразования часто являются спонтанными и непоследовательными. В исследовании определены основные компоненты институциональной структуры и институциональных преобразований. В работе также определяются современные инструменты и методы оценки эффективности институциональных преобразований, а также гипотетически определены уровни эффективности институциональных преобразований.

Результаты. На основании выполненных исследований разработана научная идея, дополняющая современную теорию инноваций и институтов, о том, что анализ и оценка эффективности инноваций и институциональных преобразований является важным инструментом стратегического планирования инновационного развития. Предложены методика исследования лесной отрасли, основанная на междисциплинарном подходе, которая включает исследование экономической и социальной подсистем с учетом экологических факторов развития и универсальная методика оценки әффективности инноваций и институциональных преобразований, основанная на социологических и эконометрических методах анализа с помощью регрессионных моделей [20]. Разработаны схема (рис.1) и программа (рис. 2) инновационно-институциональных преобразований лесной.

Введены уточненные классификации инноваций и институтов, выделены основные инновации, способствующие устойчивому развитию лесной отрасли: технологические, продуктовые, институциональные, экологические, уточнены их виды, а также новое определение институциональных отношений в лесной отрасли как сложившихся механизмов взаимодействия экономических агентов для решения противоречий, возникающих по поводу распределения прав, обязанностей и присвоения

\section{Baikal Research Journal}


результатов хозяйственной деятельности. Представлена трактовка институциональных преобразований как вида инновационной деятельности и как институциональных инноваций и предложена их классификация для дальнейшей интерпретации как формы инновационной деятельности. Понятие инновационной системы лесной отрасли как совокупности взаимосвязанных субъектов, в которую входят носители ресурсов, администрации, заинтересованные группы, клиенты, сектор исследований и разработок, сектор консалтинга, рынки, инновационные предприятия, включающее инновационный потенциал, институциональные характеристики, социально-экономические характеристики и экологические факторы лесной отрасли [22].

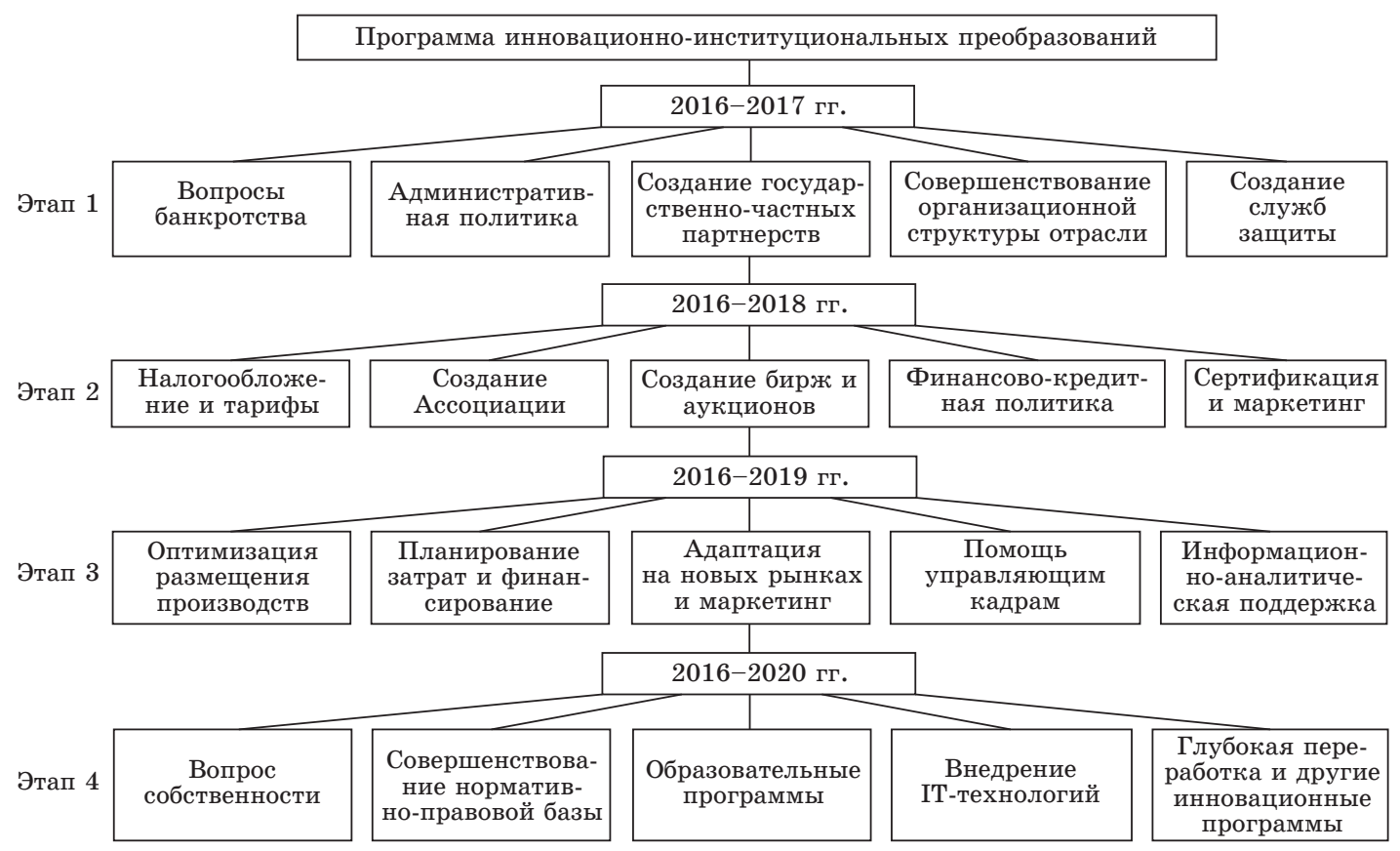

Рис. 2. Програлма инновационно-институциональных преобразований на 2016-2020 г2.

В работе изложены и систематизированы основные теоретические положения экономических учений, стратегического управления, совершенствования методического обеспечения оценки эффективности инноваций и институциональных преобразований. Раскрыты актуальные проблемы лесной отрасли и институциональные основы для ее инновационного развития [13]. Изучен и обобщен зарубежный опыт управления и инновационного развития лесной отрасли развитых стран с учетом институциональных преобразований.

Значение полученных результатов исследования для практики подтверждается тем, что разработаны и внедрены учебно-методические материалы, которые использованы в преподавании учебных курсов: «Институциональная экономика», «Региональная экономика», «Основы природопользования». Создан и апробирован инструментарий, позволяющий осуществлять более эффективную оценку и координацию действий в процессе проводимых институциональных преобразований, внедрения инноваций, как на отдельных предприятиях лесной отрасли, так и в отрасли в целом. Представлены результаты и материалы, которые использовались Иркутским научным центром и администрацией Иркутской области при разработке программ социально-экономического развития.

\section{Baikal Research Journal}


Выводы и предложения. Проведенная работа позволила сделать следующие выводы и предложения:

1. Проблемы лесной отрасли имеют межотраслевой, а в теоретическом отношении и междисциплинарный характер. Главным требованием к управлению лесами и лесной отраслью является организация неистощительного пользования ресурсами и полезностями леса, что возможно обеспечить только при условии воспроизводства на уровне неизменного масштаба. Выявленные в работе проблемы лесной отрасли, включая нехватку технологий и мощностей для глубокой переработки заготавливаемой древесины, связаны, прежде всего, с качеством институтов и с отсутствием эффективных институциональных отношений в отрасли. Проведенное исследование подтверждает выводы различных исследований, доказывающих факт существования причинно-следственной связи между качественными характеристиками институтов и институциональных отношений и широкими экономическими результатами. Институциональные инновации, являются главным типом инноваций в лесной отрасли, основой для оптимального и эффективного использования ресурсов леса.

2. Для эффективных инноваций в лесном секторе необходимо формирование современной инновационной системы лесной отрасли.

3. Для оценки эффективности институциональных преобразований предложено использование социологических, индикаторных или индикативных методов оценки и регрессионных моделей. Выбор регрессионного анализа, в рамках которого идет классификация не просто влияющих признаков, а объяснение субъективного поведения, позволяет наиболее корректно решить поставленную задачу измерения факторов и анализа эффективности инноваций и институциональных преобразований в лесной отрасли.

4. Предложенная модель оценки эффективности инноваций и институциональных преобразований и оценки экспертов подтвердили, что устойчивое развитие лесной отрасли в большей степени зависит от продуктовых инноваций и современных технологий деревообработки. Особая роль отводится IT-, нано- и биоинновациям. С помощью модели показана важность институциональных инноваций. Подтверждено, что развитие лесной отрасли зависит от формальных и неформальных институтов

5. Для совершенствования работы федеральных и региональных властей необходимо поставить цели и создать условия для их реализации в развитии лесной отрасли. Особенно важно отметить роль государственного регулирования, направленного на реализацию высокоэффективных инновационных проектов за счет гарантии по заемным кредитам, налоговых и таможенных преференций, финансирования приоритетных научных инновационных проектов и малых инновационных предприятий.

6. Предложена программа инновационно-институциональных преобразований, которая включает четыре этапа для решения следующих вопросов:

- вопросы банкротств, административной политики, создания государственно-частных партнерств, совершенствования организационной структуры, создания служб защиты;

- налогообложения и тарифов; создания ассоциации, создания бирж и аукционов, финансово-кредитной политики, сертификации и маркетинга;

- оптимизации размещения производств, планирования затрат и финансирования, разработки методов стимулирования инновационной деятельности, помощи управляющим кадрам, информационно-аналитической поддержки;

- вопросов собственности, совершенствования нормативно-правовой базы, образовательных программ, внедрения IT-технологий, глубокой переработки и других инновационных программ.

\section{Baikal Research Journal}


7. Предложен ряд мер стимулирующего порядка по развитию инноваций в лесной отрасли. Особенно важным является стимулирование проектов глубокой деревообработки и производства продукции с более высокой добавленной стоимостью, а также проектов производства абсолютно новой продукции, такой как биотопливо и новые композитные материалы. Необходимо финансово стимулировать частный бизнес к развитию деревообработки с использованием новейших технологий и производства новых материалов. Необходима поддержка государства для создания научных центров, занимающихся разработкой, поиском и адаптацией инноваций в лесной отрасли. Выделяемые финансовые средства должны быть направлены на решение проблем стратегического характера по инновационному развитию лесной отрасли.

8. Важно развитие транспортной инфраструктуры, реализация инвестиционных проектов, строительство линейных объектов и многое другое неразрывно связано с лесоустройством, которое должно производиться систематически и непрерывно. Помимо организации охраны лесного фонда от незаконных действий необходимо заинтересовать предпринимателей в легализации лесозаготовки с преимущественным правом для тех предприятий, которые ранее ее осуществляли, не нарушали законодательство и прошли добровольную лесную сертификацию.

\section{Список использованной литературы}

1. Балацкий Е. Роль государственного сектора в построении «новой экономики»/ Е. Балацкий, В. Конышев // Общество и экономика. - 2004. - № 2. - С. 86-99.

2. Грачева М. В. Инновационное предпринимательство, его риски и обеспечение безопасности / М. В. Грачева, А. С. Кулагин, С. Ю. Симаранов // Инновации. - 2002. № 1. - С. 59-64.

3. Фатхутдинов Р. А. Инновационный менеджмент : учебник / Р. А. Фатхутдинов. 5-е изд. - СПб. : Питер, 2005. - 448 с.

4. Коуз Р. Фирма, рынок и право : сб. ст. / Р. Коуз ; пер. с англ. Б. Пинскера ; науч. ред. Р. Капелюшников. - М. : Нов. изд-во, 2007. -224 с.

5. Норт Д. Институты, институциональные изменения и функционирование экономики / Д. Норт ; пер. с англ. А. Н. Нестеренко ; науч. ред. Б. З. Мильнер. - М. : Начала, 1997. $-180 \mathrm{c}$.

6. Институциональная экономика. Новая институциональная экономическая теория : учебник / под ред. А. А. Аузана. - М. : Инфра-М, 2005. - 416 с.

7. Белокрылова О. С. Институциональные особенности распределения доходов в переходной экономике / О. С. Белокрылова, В. В. Вольчик, А. А. Мурадов. - Ростов н/Д. : Изд-во Ростов. гос. ун-та, 2000. - 111 с.

8. Калюжнова Н. Я. Институциональная экономика: общий курс : учеб. пособие / Н. Я. Калюжнова, Ю. В. Долгов, М. А. Осипов ; под ред. Н. Я. Калюжновой. - Иркутск : Изд-во Иркут. гос. ун-та, 2012. - 139 с.

9. Полтерович В. М. Трансплантация экономических институтов / В. М. Полтерович // Экономическая наука современной России. - 2001. - № 3. - С. 24-50.

10. Шумпетер Й. А. Капитализм, социализм и демократия : пер. с англ. / Й. А. Шумпетер ; под общ. ред. В. С. Автономова. - М. : Наука, 2007. - 540 с.

11. Заркович А. В. Теории инновационного развития: концепция региональных инновационных систем [Электронный ресурс] / А. В. Заркович // Гуманитарные научные исследования. - 2013. - № 6. - Режим доступа: http://humans.nauka.ru/2013/06/3404.

12. Машкина О. В. Институциональный анализ экономики лесного комплекса : дис. ... канд. экон. наук : 08.00.05 / О. В. Машкина. - Новосибирск, 2003. - 157 с.

13. Дайнеко Д. В. Актуальные проблемы развития лесной отрасли Иркутской области [Электронный ресурс] / Д. В. Дайнеко, А. П. Черников // Известия Иркутской государственной экономической академии (Байкальский государственный университет экономики и права). - 2012. - № 3. - Режим доступа: http://eizvestia.isea.ru/reader/article.aspx?id=13588.

14. Биянова Н. 70\% территории России будет приватизировано [Электронный ресурс] / Н. Биянова, В. Баринов // FLB.ru: агентство федеральных расследований. - Режим доступа: http://flb.ru/info/24780.htm.

\section{Baikal Research Journal}


15. Ruttan V. W. Social Science Knowledge and Induced Institutional Innovation: An Institutional Design Perspective [Electronic resource] / V. W. Ruttan // Journal of Institutional Economics. - 2005. - Vol. 2, iss. 3. - P. 249-272. - Mode of access: http://www.indiana. edu/ workshop/colloquia/materials/papers/ruttan_paper.pdf.

16. Knight J. Institutions and Social Conflict / J. Knight. - Cambridge : Cambridge University Press, 1992. - 234 p.

17. Тамбовцев В. Л. Теория институциональных изменений : учеб. пособие / В. Л. Тамбовцев. - М. : Инфра-М, 2008. - 152 с.

18. Олейник А. Н. Институциональная экономика : учеб. пособие / А. Н. Олейник. М. : Инфра-М, 2002. - 416 с.

19. Дайнеко Д. В. Эффективность инноваций и институциональных преобразований в лесной отрасли / Д. В. Дайнеко // Эволюция научной мысли : сб. ст. Междунар. науч.-практ. конф. : в 2 т. / отв. ред. А. А. Сукиасян. - Уфа : Аэтерна, 2014. - Т. 2. - С. 18-23.

20. Дайнеко Д. В. Регрессионный анализ как инструмент оценки эффективности инноваций на примере лесной отрасли / Д. В. Дайнеко, Н. А. Потороченко // Информационные и математические технологии в науке и управлении : материалы XX Байкал. Всерос. конф. / отв. ред. Л. В. Массель. - Иркутск : Ин-т систем энергетики им. Л. А. Мелентьева Сиб. отд-ния РАН, 2015. - Ч. І. - С. 31-36.

21. Курнышева И. Условия инновационного развития / И. Курнышева / Экономист. 2001. - № 7. - С. 9-18.

22. Дайнеко Д. В. Инновационное предпринимательство и его стимулирование в лесной отрасли Иркутской области / Д. В. Дайнеко // Управление человеческими ресурсами - основа развития инновационной экономики : сб. материалов Междунар. науч.-практ. конф. Красноярск, 20-21 марта 2014 г. - Красноярск : Изд-во Сиб. гос. аэрокосм. ун-та, 2014. - С. 37-45.

\section{References}

1. Balatsky E., Konyshev V. Role of governmental sector in building «new economy». $O b$ shchestvo i ekonomika = Science and Economy, 2004, no. 2, pp. 86-99. (In Russian).

2. Gracheva M. V., Kulagin A. S., Simaranov S. Yu. Innovative entrepreneurship, its risks and security provision. Innovatsii = Innovations, 2002, no. 1, pp. 59-64. (In Russian).

3. Fatkhutdinov R. A. Innovatsionnyi menedzhment [Innovation Management]. $5^{\text {th }}$ ed. Saint Petersburg, Piter Publ., 2005. 448 p.

4. Coase Ronald. The Firm, the Market and the Law. Chicago, London, The University of Chicago Press, 224 p. (Russ. ed.: Coase R. Firma, rynok i pravo. Moscow, Novoe izdatel'stvo Publ., 2007. 224 p.).

5. North Douglass. Institutional Change and Economic Performance. Cambridge University Press, 1990. 159 p. (Russ. ed.: North D. Instituty, institutsionalnye izmeneniya $i$ funktsionirovanie ekonomiki. Moscow, Nachala Publ., 1997. 180 p.).

6. Auzan A. A. (ed.). Institutsional'naya ekonomika. Novaya institutsional'naya ekonomicheskaya teoriya [Institutional Economics. New institutional economic theory]. Moscow, Infra-M Publ., 2005. 416 p.

7. Belokrylova O. S., Vol'chik V. V., Muradov A. A. Institutional features of distributing incomes in transitional economy. Rostov-on-Don, Rostov State University Publ., 2000. 111 p.

8. Kalyuzhnova N. Ya., Dolgov Yu. V., Osipov M. A. Institutsional'naya eko-nomika: obshchii kurs [Institutional Economics: General Course]. Irkutsk State University Publ., 2012. 139 p.

9. Polterovich V. M. Transplantation of economic institutes. Ekonomicheskaya nauka sovremennoi Rossii = Economic Science of Modern Russia, 2001, no. 3, pp. 24-50. (In Russian).

10. Schumpeter Joseph A. Capitalism, Socialism and Democracy. New York, Harper \& Bros., 1942. 163 p. (Russ. ed.: Schumpeter J. A.; Avtonomova V. S. (ed.). Kapitalizm, sotsializm i demokratiya. Moscow, Nauka Publ., 2007. 540 p.).

11. Zarkovich A. V. The theories of innovative development: the concept of regional innovation systems. Gumanitarnye nauchnye issledovaniya = Humanities Scientific Researches, 2013, no. 6. Available at: http://humans.nauka.ru/2013/06/3404. (In Russian).

12. Mashkina O. V. Institutsional'nyi analiz ekonomiki lesnogo kompleksa. Kand. Diss. [Institutional analysis of timber complex economy. Cand. Diss.]. Novosibirsk, 2003. 157 p.

13. Daineko D. V., Chernikov A. P. Current problems of forest industry development in Irkutsk Oblast. Izvestiya Irkutskoi gosudarstvennoi ekonomicheskoi akademii (Baykalskii gosu-

\section{Baikal Research Journal}


darstvennyyii universitet ekonomiki i prava) $=$ Bulletin of Irkutsk State Economics Academy (Baikal State University of Economics and Law), 2012, no. 3. Available at: http://eizvestia. isea.ru/reader/article.aspx?id=13588. (In Russian).

14. Biyanova N., Barinov V. $70 \%$ of Russia's territory will be privatized. FLB.ru: agentst vo federal'nykh rassledovanii [FLB.ru: Agency of Federal Investigations]. Available at: http:// flb.ru/info/24780.htm. (In Russian).

15. Ruttan V. W. Social Science Knowledge and Induced Institutional Innovation: An Institutional Design Perspective. Journal of Institutional Economics, 2005, vol. 2, iss. 3, pp. 249-272. Available at: http://www.indiana.edu/ workshop/colloquia/materials/papers/ ruttan_paper.pdf.

16. Knight J. Institutions and Social Conflict. Cambridge University Press, 1992. $234 \mathrm{p}$.

17. Tambovtsev V. L. Teoriya institutsional'nykh izmenenii [Theory of institutional changes]. Moscow, Infra-M Publ., 2008. $152 \mathrm{p}$.

18. Oleinik A. N. Institutsional'naya ekonomika [Institutional Economics]. Moscow, Infra-M Publ., 2002. 416 p.

19. Daineko D. V. Efficiency of innovations and institutional changes in the timber industry. In Sukiasyan A. A. (ed.). Evolyutsiya nauchnoi mysli. Materialy Mezhdunarodnoi nauchno-prakticheskoi konferentsii [Evolution of scientific thought. Materials of International Research Conference]. Ufa, Aeterna Publ., 2014, vol. 2, pp. 18-23. (In Russian).

20. Daineko D. V., Potorochenko N. A. Regressive analysis as a tool of assessing efficiency innovations using the example of the timber industry. In Massel' L. V. (ed.). Informatsionnye i matematicheskie tekhnologii $v$ nauke $i$ upravlenii. Materialy XX Baikal'skoi Vserossiiskoi konferentsii [Information and mathematical technologies in science and management. Materials of 20th Baikal All-Russian Conference]. Irkutsk, Melentiyev Energy Systems Institute Siberian Branch of the Russian Academy of Sciences Publ., 2015, pr. 1 pp. 31-36. (In Russian).

21. Kurnysheva I. Terms of innovative development. Ekonomist. 2001, no. 7, pp. 9-18. (In Russian).

22. Daineko D. V. Innovative entrepreneurship and its encouragement in the timber industry of the Irkutsk Oblast. Upravlenie chelovecheskimi resursami - osnova razvitiya innovatsionnoi ekonomiki. Materialy mezhdunarodnoi nauchno-prakticheskoi konferentsii. Krasnoyarsk, 20-21 marta $2014 \mathrm{~g}$. [Human resource management as a basis for the development of innovative economics. Materials of International Research Conference. Krasnoyarsk, March 20-21, 2014]. Krasnoyarsk, Siberian State Aerospace University Publ., 2014, pp. 37-45. (In Russian).

\section{Информация об авторе}

Дайнеко Денис Валерьевич - кандидат экономических наук, научный сотрудник Иркутского научного центра Сибирского отделения Российской академии наук, 664033, г. Иркутск, ул. Лермонтова, 134-117; доцент, Иркутский национальный исследовательский технический университет, 664074, г. Иркутск, ул. Лермонтова, 83; e-mail: dayneko@oresp.irk.ru.

\section{Author}

Denis V. Daineko - PhD in Economics, Research Worker, Irkutsk Science Center of SB RAS, 134-117, Lermontov St., 664033, Irkutsk, Russian Federation; Associate Professor, Irkutsk National Research Technical University, 83 Lermontov St., 664074, Irkutsk, Russian Federation; e-mal: dayneko@oresp.irk.ru.

\section{Библиографическое описание статьи}

Дайнеко Д. В. Эффективность институциональных преобразований как основа развития инновационной деятельности в лесной отрасли / Д. В. Дайнеко // Baikal Research Journal. — 2016. - T. 7, № 6. — DOI: 10.17150/2411-6262.2016.7(6).6.

\section{Reference to article}

Dayneko D. V. Efficiency of institutional changes as a basis of developing innovative activity in timber industry. Baikal Research Journal, 2016, vol. 7, no. 6. DOI : 10.17150/24116262.2016.7(6).6. (In Russian).

\section{Baikal Research Journal}

